\title{
The role of fortitude in relation to exposure to violence among adolescents living in lower socio-economic areas in South Africa
}

\author{
Tyrone B. Pretorius, Anita Padmanabhanunni and Jerome Campbell
}

\begin{abstract}
Objective: There is compelling evidence that a significant proportion of adolescents exposed to violence do not develop trauma-related symptoms, but adapt successfully. This differential vulnerability has propelled research into identifying factors that promote coping. This study focused on the role of fortitude in the relationship between violence and trauma-related symptoms among South African adolescents living in two low-income communities. Fortitude is derived from positive cognitive appraisals of the self, the family and external sources of support.

Method: Adolescents $(n=498)$ completed an adapted version of the Harvard Trauma Scale (HTS) and the Fortitude Questionnaire (FORQ).

Results: Moderated regression analysis demonstrated that fortitude had a health-sustaining and stress- buffering role. Adolescents who displayed high levels of fortitude had lower levels of trauma symptoms in relation to exposure to violence (stress-buffering) and were able to maintain their levels of wellbeing irrespective of the nature and extent of such exposure (health-sustaining).

Conclusion: The study provides evidence for fortitude as a protective factor by highlighting the role of specific cognitive appraisals related to fortitude in facilitating adaptation in relation to trauma. The study also underscores the relevance of using clinical interventions that target problematic cognitive appraisals and strengthen perceptions of coping.
\end{abstract}

South African adolescents live in a context characterised by high levels of exposure to violence. The homicide rate in the country is 5 times the global average with the highest victimisation rates seen in young men aged 15-29 years (Harris \& Vermaak, 2015; Seedat van Niekerk, Jewkes, Suffla, \& Ratele, 2009; Ward et al., 2012). The rate of homicide of women by an intimate partner is 6 times the global average with women between the ages of 14 and 44 years being at most risk (Gass, Stein, Williams, \& Seedat, 2011). Research findings also indicate that $39 \%$ of young girls have experienced some form of sexual abuse (e.g., sexual molestation, exploitation by an older man) before the age of 18 years. Furthermore, many children and adolescents are exposed to domestic violence and neglect with some findings indicating that $45 \%$ of children have witnessed their mother being beaten or have experienced both of their parents being too drunk to look after them (Shields, Nadasan, \& Pierce 2008; Ward et al., 2012). 
Exposure to violence has consistently been associated with negative psychological outcomes among adolescents (e.g., post-traumatic stress disorder (PTSD), depression and substance abuse) (Atwoli et al., 2013) and, as a result, considerable research efforts have focused on developing effective psychological interventions to address these outcomes (Ford, Grasso, Elhai, \& Courtois, 2015). However, also important in successful intervention is an understanding of differential vulnerability (Zolkoski \& Bullock, 2012). Increasingly, there has been recognition that, while many children and adolescents exposed to trauma develop chronic difficulties, a significant proportion of youth demonstrate relatively positive adjustment and competent functioning despite their experience (Bonanno \& Diminich, 2013; Noltemeyer $\&$ Bush, 2013). This variability in response to adverse life experiences points to the influence of specific protective factors. From an intervention perspective, the identification of such factors can allow for tailored interventions that are specifically designed to enhance those factors associated with effective coping and reduce the probability of negative outcomes.

Some of the protective factors that have already been identified in the literature as facilitating coping among adolescents exposed to violence include family cohesion, parental support, self-efficacy, high intelligence, having an internal locus of control and using active problem-solving skills (Copeland-Linder, Lambert, \& Ialongo, 2010; Hardaway, McLoyd, \& Wood, 2012; Jain, Buka, Subramanian, \& Molnar, 2012; O’Donnell, Roberts, \& SchwabStone, 2011). Shields et al. (2008), for example, found that social support and family organisation (e.g., parental supervision and monitoring) were associated with lower levels of psychological distress related to exposure to violence among children living in low income settings in South Africa. Hardaway et al. (2012) reported that high levels of participation in extra-curricular activities and positive parent-child relations served as protective factors for adolescents exposed to violence in low-income communities. O'Donnell et al. (2011) found that a positive school environment buffered the impact of exposure to violence among youth.

This study focused on fortitude as a potential protective factor. Fortitude is defined as the strength to manage stress and stay well and is derived from positive cognitive appraisals of the self (e.g., as competent and capable), the family (e.g., as reliable, trustworthy and supportive) and external sources of support (e.g., as available, accessible and potentially beneficial) (Pretorius, 1998). The construct of fortitude is similar to resilience in its ability to facilitate coping, but it differs from resilience in that it is based purely on a theory of appraisal (Pretorius, 1998). In other words, it is not so much the objective factors that are considered (e.g., family support, school environment), but how such factors are appraised that is seen as influencing psychological outcome.

The role of cognitive appraisals in outcome following exposure to traumatic events has been well documented (Bovin \& Marx, 2011; DePrince, Chu, \& Pineda, 2011; Janoff-Bulman 2010). Several cognitive theorists (Janoff-Bulman, 2010; Kleim et al., 2013; Park, Mills, \& Edmondson, 2012) have proposed that people function on the basis of certain basic assumptions (e.g., that the self is worthwhile, other people are benevolent and that the world is a relatively safe place) and that the experience of trauma challenges these beliefs 
and evokes considerable distress. To cope, people engage in cognitive processes by appraising the potential impact of the event and evaluating what coping resources are available and accessible to them (Calhoun \& Tedeschi, 2014). The outcome of this cognitive process then determines their adjustment (Yeung, Lu, Wong, \& Huynh, 2015).

The role of fortitude in adjustment has been investigated in relation to a range of challenging life circumstance. Pretorius, Walker and Heyns (2009) explored the experience of men caring for spouses suffering from dementia and found that positive appraisals of the self, their family environments and their recognition of support from others led to participants experiencing their caregiving more meaningfully. In a similar study, Potgeiter and Heyns (2006) investigated the experiences of female spouses caring for partners with Alzheimer's disease. Participants in the study had low levels of fortitude and this was related to, among other aspects, negative appraisals regarding their ability to cope and reduced self-confidence as well as perceptions related to the ability of family members to share the burden of caregiving. Heyns, Venter, Esterhuyse, Bam and Odendal (2003) investigated fortitude among nurses caring for Alzheimer's patients and found a negative correlation between burnout and fortitude in that lower levels of fortitude were associated with increased risk of burnout. Van Schalkwyk and Wissing (2013), in a study on the effect of a psychosocial wellbeing programme for adolescents, found that the intervention increased levels of fortitude, which contributed to enhanced wellbeing. De Villiers and van den Berg (2012) used the fortitude scale to investigate the impact of a resilience programme among 12-year-old children and found that self-appraisals increased significantly following administration of the programme.

Few studies have investigated fortitude in relation to exposure to violence. This type of research is particularly salient given that South African adolescents, particularly those in disadvantaged community settings, grow up in environments characterised by high levels of violence (Swart, Seedat, \& Nel, 2015; Ward et al., 2012). Identifying factors that may buffer the impact of such exposure and promote effective coping is crucial for developing interventions tailored to particular contexts and populations.

Shumaker and Brownell (1984) hypothesised that there are two pathways through which a third variable (fortitude) can influence the relationship between a dependent (psychological outcome) and an independent variable (exposure to violence), namely a direct (healthsustaining) and a buffering pathway (stress-reducing). The direct effect hypothesis would postulate that high levels of fortitude will result in an increase in psychological wellbeing, irrespective of the level of stress (i.e. exposure to violence). The buffering hypothesis would suggest that at low levels of fortitude, the relationship between violence and psychological wellbeing should be strong and direct (that is, high violence levels are associated with low levels of psychological wellbeing), and as fortitude increases the relationship should weaken. 


\section{Method \\ Setting}

The study was conducted in two lower socio-economic communities in the Western Cape province of South Africa namely, Manenberg and Hanover Park. These communities were established during the apartheid era as a result of the Group Areas Act, in terms of which individuals classified as Black, Coloured (a South African ethnic group of mixed ancestry) and Indian were forcibly relocated to specific parts of the country. These contexts are currently characterised by socio-economic inequality, high rates of substance abuse and community violence (Seedat et al., 2009).

\section{Sample}

Participants were adolescents $(n=498)$ attending Grades 8 to 12 in two lower socioeconomic communities in the Western Cape province of South Africa. A description of the sample is presented in Table 1.

Table 1: Description of sample

\begin{tabular}{|c|c|c|c|}
\hline Demographic & & $N$ & $\%$ \\
\hline \multirow{2}{*}{ Gender } & Male & 243 & 48.8 \\
\hline & Female & 255 & 51.2 \\
\hline \multirow[t]{7}{*}{ Age } & 14 & 148 & 30.2 \\
\hline & 15 & 258 & 52.7 \\
\hline & 16 & 18 & 3.7 \\
\hline & 17 & 21 & 4.3 \\
\hline & 18 & 45 & 9.2 \\
\hline & Mean & & 15.1 \\
\hline & $\mathrm{SD}$ & & 1.15 \\
\hline \multirow[t]{3}{*}{ Language } & English & 143 & 28.8 \\
\hline & Afrikaans & 349 & 70.2 \\
\hline & African & 5 & 1.0 \\
\hline \multirow[t]{5}{*}{ Grade } & 8 & 143 & 28.7 \\
\hline & 9 & 240 & 48.2 \\
\hline & 10 & 45 & 9.0 \\
\hline & 11 & 19 & 3.8 \\
\hline & 12 & 51 & 10.2 \\
\hline \multirow[t]{2}{*}{ Area } & Manenberg & 438 & 88 \\
\hline & Hanover Park & 60 & 12 \\
\hline \multirow{2}{*}{ Number of people in house } & Mean & & 6.3 \\
\hline & SD & & 2.48 \\
\hline
\end{tabular}

The numbers of boys and girls in the sample were roughly equal. The mean age was 15.10 ( $\mathrm{SD}=1.15)$ and most participants were in Grade 9. The home language of most of the 
sample was Afrikaans (70.1\%). The mean household size for the sample was 6.30 (SD = 2.48; minimum $=2$, maximum $=20$ ).

\section{Instruments}

Two self-report instruments were used, the Harvard Trauma Questionnaire (HTQ) (Mollica et al., 1992) and the Fortitude Questionnaire (FORQ) (Pretorius, 1998) which were translated into Afrikaans and back-translated into English to ensure accuracy. Exposure to violence was assessed using the HTQ. This scale was originally developed to assess the traumatic experiences of Indo-Chinese refugees in the United States and focuses on both the assessment of traumatic experiences as well as trauma symptoms. This scale was subsequently adapted for use among South African adolescents by focusing on violent events that are most likely to occur in the country (Ward et al., 2001). The first section of the HTQ consists of 49 questions focusing on a variety of violent events. The adapted version of this first section also differed from the original in terms of format. The original version allowed for four response categories, namely "experienced", "witnessed", "heard" or "no". The revised version only provided a "yes" or "no" option, but different types of questions were included that allowed for the assessment of different types of exposure to violence (i.e., as witness or victim). The revised format thus allowed for the calculation of a total exposure score and a separate score for different categories of exposure (i.e., witnessing stranger violence, victim of stranger violence, witnessing known violence, victim of known violence).

The second part of the HTQ consisted of 30 symptom questions where the first 16 were derived from the DSM-IIIR/DSM-IV criteria for PTSD. The remaining 14 questions described additional symptoms that may result from traumatic events, but are not required for diagnosis. This section of the scale provided four response options ranging from "not at all" to "extremely". A total trauma- related symptoms score is obtained by summing the responses to the 30 questions. The HTQ has been used in diverse contexts (Mollica et al. (1992) - Indo-Chinese refugees; Renner, Salem and Ottomeyer (2006) Chechens, Afghans and West Africans; and Ward et al., (2001) - adolescent South Africans). In all these studies the HTQ has demonstrated sound reliability with reliability coefficients ranging between 0.90 and 0.96 .

The FORQ consists of 20 items and uses a 4-point scale ranging from "does not apply" to "applies very strongly". These 20 items measure 3 domains, namely self-appraisals, family appraisals and support appraisals. The sum of the three domains represents fortitude. In the initial validation study Pretorius (1998) reported coefficient alphas of between 0.74 and 0.82 for the subscales and a coefficient of 0.85 for the full scale. The content validity of the FORQ was assured through the process of item selection, while both exploratory and confirmatory factor analyses supported the three-factor structure of the FORQ. The FORQ also correlated with measures of psychological distress as well as with measures of selfappraisal (i.e., self-esteem), social support and family environment. Additional support for the reliability and validity of the FORQ has come from several South African studies that have reported reliability coefficients between 0.77 and 0.88 (Heyns et al., 2003; Wissing, 
Wissing, du Toit, \& Temane, 2006; Wissing \& Temane, 2013). These authors also used structural equation modelling to confirm the factor structure of the FORQ. The FORQ has also been used with adolescents by Van Schalkwyk and Wissing (2013) and demonstrated sensitivity to the impact of a wellbeing intervention.

\section{Procedure}

Questionnaires were administered over a period of two weeks. The language preference of each class determined whether questionnaires were administered in English or Afrikaans. The nature and aims of the research were described to each class, as were the content and completion requirements of the questionnaire. All questions were read aloud and adolescents were given time after the reading of each item to respond in the space provided on their questionnaires. All questionnaires were completed anonymously.

\section{Analysis}

To examine the direct and moderating effects of fortitude, moderated regression analyses (Cohen \& Cohen, 1975) were performed. In moderated regression analyses the psychological outcome (in this instance, trauma symptoms) is used as the dependent variable in a two-step regression analysis. The scores of the adverse condition (exposure to violence) and the presumed moderating variable (fortitude) are entered together in the regression equation in Step 1, while an interaction term (the product of fortitude and the various violence subscales) is entered in Step 2. To avoid the problem of multicollinearity, the deviation scores (score minus mean) of the adverse condition and the presumed moderating variable are used in the calculation of the product term (Good \& Hardin, 2012; Finney, Mitchell, Cronkite, \& Moos, 1984). A significant effect for fortitude in Step 1 indicates a direct effect for fortitude (i.e., a health-sustaining effect). A significant effect for the product term in Step 2 indicates that fortitude has a moderating effect.

\section{Results}

The means, standard deviations and reliability coefficients (coefficient alpha) for the scales (and subscales) are reported in Table 2.

The reliability of all the scales is generally satisfactory except the "Witness to stranger violence" subscale which, although acceptable, is below the accepted convention for satisfactory reliability. This is largely due to the low number of items in this scale. Conclusions and results based on this scale should be viewed with caution.

The inter-correlations between the various scales are reported in Table 3 .

Table 3 indicates a significant positive relationship between all of the violent subscales and the trauma-related symptoms. This implies that an increase in exposure to violence is significantly associated with an increase in trauma-related symptoms. Fortitude, however, is significantly negatively related to trauma-related symptoms, indicating that higher levels of fortitude are associated with lower levels of trauma-related symptoms. 
The results of the moderated regression analyses with trauma-related symptoms as dependent variable are indicated in Table 4.

Table 2: Means, standard deviations and reliability coefficients of measures

\begin{tabular}{lcrcc}
\hline Scale & No. of items & Mean & SD & Alpha \\
\hline Total violence & 49 & 13.47 & 7.91 & 0.91 \\
Victim of known violence & 16 & 2.80 & 2.47 & 0.76 \\
Witness to known violence & 18 & 5.30 & 3.47 & 0.81 \\
Victim of stranger violence & 9 & 1.42 & 1.77 & 0.75 \\
Witness to stranger violence & 6 & 3.96 & 1.40 & 0.60 \\
Traumatic symptoms & 30 & 54.01 & 18.45 & 0.94 \\
Fortitude & 20 & 55.26 & 9.15 & 0.76 \\
\hline
\end{tabular}

Table 3: Intercorrelations between violence subscales, fortitude and trauma symptomatology

\begin{tabular}{|c|c|c|c|c|c|c|}
\hline & $\begin{array}{l}\text { Victim } \\
\text { known }\end{array}$ & $\begin{array}{l}\text { Witness } \\
\text { known }\end{array}$ & $\begin{array}{l}\text { Victim } \\
\text { stranger }\end{array}$ & $\begin{array}{l}\text { Witness } \\
\text { stranger }\end{array}$ & Fortitude & $\begin{array}{l}\text { Trauma } \\
\text { symptoms }\end{array}$ \\
\hline Violence & $0.87^{\star \star \star}$ & $0.93^{\star \star}$ & $0.85^{\star \star}$ & $0.73^{\star \star}$ & $-0.24^{\star \star}$ & $0.60^{\star \star}$ \\
\hline Victim known & 1 & $0.72^{\star \star}$ & $0.74^{\star \star}$ & $0.46^{\star \star}$ & $-0.21^{\star \star}$ & $0.56^{\star \star}$ \\
\hline Witness known & & 1 & $0.68^{\star \star}$ & $0.66^{\star \star}$ & $-0.22^{\star \star}$ & $0.54^{\star *}$ \\
\hline Victim stranger & & & 1 & $0.52^{\star \star \star}$ & $-0.24^{\star \star}$ & $0.55^{\star \star}$ \\
\hline Witness stranger & & & & 1 & $-0.16^{\star \star}$ & $0.36^{\star \star}$ \\
\hline Fortitude & & & & & 1 & $-0.24^{\star \star}$ \\
\hline
\end{tabular}

${ }^{* \star} p<0.01$

The moderated regression analyses in Table 4 indicate a significant direct effect for fortitude on trauma-related symptoms when considered together with all the violence subscales. This would imply a health-sustaining role for fortitude in respect of traumarelated symptoms. In addition, the product-term of fortitude and witness to stranger violence was also significant. This would imply a stress-buffering role for fortitude in respect of the impact of witness to stranger violence on trauma- related symptoms. The exact nature of the interaction/moderating effect can be established by comparing the regression lines of those low on fortitude with those high on fortitude. Following the procedure suggested by Cohen and Cohen (1975), two different regression lines were computed, namely one for those high in fortitude (at or above the 75th percentile, $N=138$ ) and one for those low in fortitude (at or below the 25th percentile, $N=125$ ). These are shown in Figure 1.

The regression line for those low in fortitude was much steeper (slope $=6.00$ ) than the regression line of those high in fortitude (slope $=3.08$ ). This indicates that an increase in exposure to stranger violence is more strongly associated with an increase in trauma symptoms for those low in fortitude compared to those high in fortitude. 


\section{Discussion}

This study investigated the health-sustaining and stress-reducing roles of fortitude among adolescents exposed to violence. Consistent with the existing literature (Jones, 2007; Suliman, Mkabile, Fincham, Ahmed, Stein, \& Seedat, 2009) the study found a significant positive relationship between all of the violent subscales and trauma-related symptoms, indicating that an increase in exposure to violence is significantly associated with an increase in trauma-related symptoms.

There was a significant direct effect for fortitude on trauma-related symptoms when considered with all the violence subscales. This indicates a health-sustaining role for fortitude in respect of trauma-related symptoms in that adolescents who displayed high levels of fortitude were able to maintain their levels of wellbeing irrespective of the nature and extent of exposure to violence. The direct effects hypothesis postulates that the effect of a third variable (fortitude), on wellbeing is independent of the level of the negative environmental conditions (exposure to violence). Also, an increase in the levels of fortitude will result in an increase in wellbeing, irrespective of the level of stress (in this case, exposure to violence).

Table 4: Moderated regression analyses with trauma symptoms as dependent variable

\begin{tabular}{|c|c|c|c|c|}
\hline Predictor & $\mathrm{df}$ & $t$ & Cum $R^{2}$ & Beta \\
\hline Total violence & 1484 & $15.52^{\star \star \star}$ & 0.36 & 0.58 \\
\hline Fortitude & 1484 & $-2.92^{\star \star}$ & 0.37 & -0.11 \\
\hline Fortitude $\times$ Violence & 1483 & -0.79 & 0.37 & -.03 \\
\hline Victim known & 1488 & $14.50^{\star \star}$ & 0.33 & 0.54 \\
\hline Fortitude & 1488 & $-3.64^{\star \star}$ & 0.34 & -0.14 \\
\hline Fortitude $\times$ Victim known & 1487 & 0.03 & 0.34 & 0.01 \\
\hline Witness known & 1489 & $13.07^{\star \star \star}$ & 0.29 & 0.51 \\
\hline Fortitude & 1489 & $-3.48^{\star \star}$ & 0.30 & -0.14 \\
\hline Fortitude $\times$ Witness known & 1488 & -1.89 & 0.30 & -0.07 \\
\hline Victim stranger & 1488 & $13.74^{\star \star}$ & 0.31 & 0.53 \\
\hline Fortitude & 1488 & $-3.10^{\star \star}$ & 0.32 & -0.12 \\
\hline Fortitude $\times$ Victim stranger & 1487 & -0.10 & 0.32 & -0.01 \\
\hline Witness stranger & 1489 & $7.91^{\star \star}$ & 0.13 & 0.33 \\
\hline Fortitude & 1489 & $-4.57^{\star \star}$ & 0.17 & -0.19 \\
\hline Fortitude $\times$ Witness stranger & 1488 & $-2.76^{\star \star}$ & 0.18 & -0.11 \\
\hline
\end{tabular}

${ }^{a}$ Represents different steps in regression analyses; ${ }^{* \star} p<0.01$ 


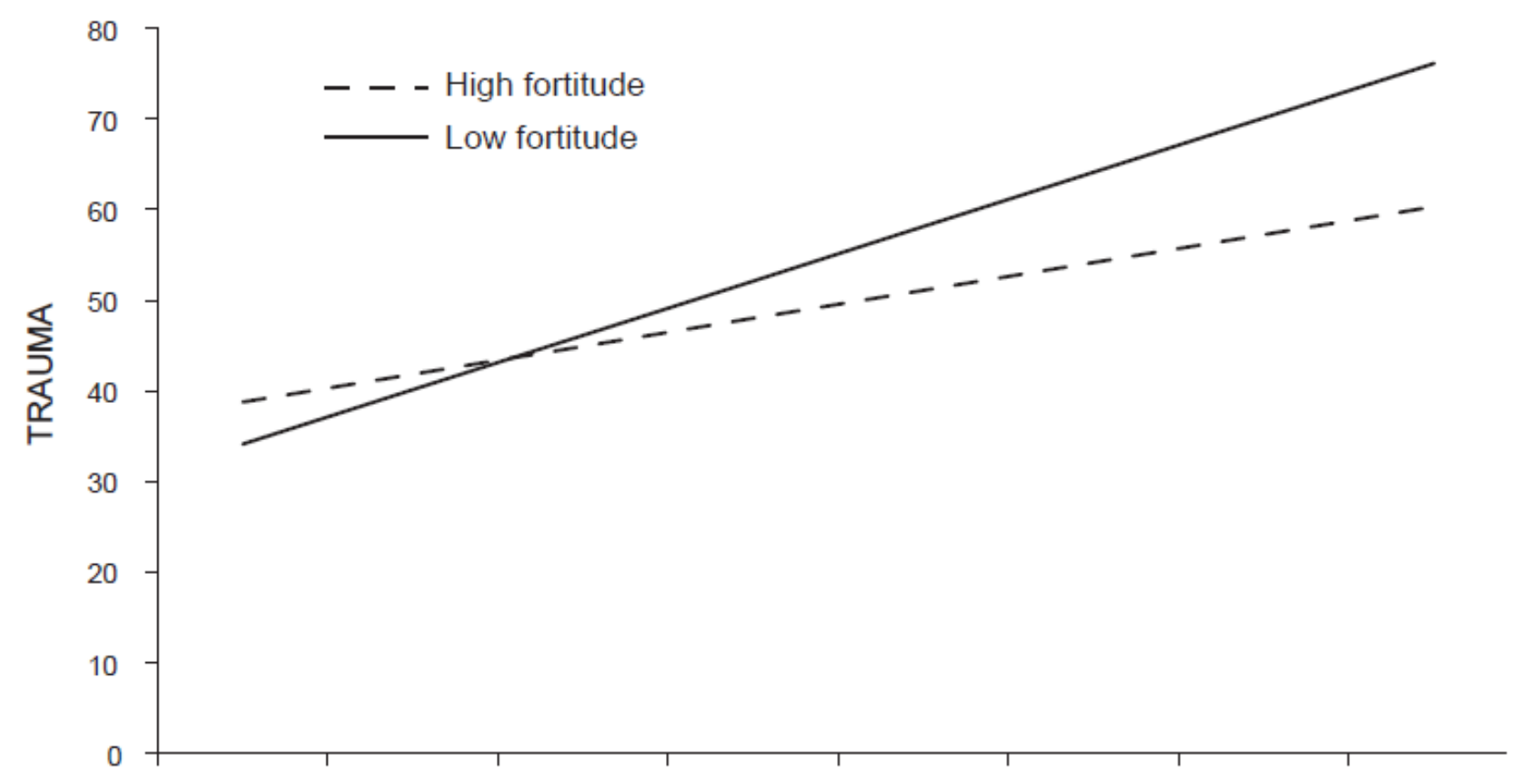

WITNESS STRANGER VIOLENCE

Figure 1: Regression of trauma symptoms on witness to stranger violence for high and low fortitude

Other studies that have looked at the direct effects of a third variable have also found similar significant relationships. For example, Pretorius et al. (2009) found that sense of coherence was associated with coping among a sample of men caring for spouses suffering from dementia. Pretorius (1992) found that problem-solving appraisal was directly associated with depression in a sample of African South African university students.

The results further suggest a significant relationship between fortitude and "witness to stranger violence" in the adolescent sample, indicating a stress buffering role for fortitude in respect of the impact of "witness to stranger violence". This means that witnessing stranger violence is more strongly associated with an increase in trauma symptoms for those low in fortitude compared to those high in fortitude. Some literature supports the stress-buffering role of fortitude. Pretorius (1998) found that undergraduate students with high levels of stress and high levels of wellbeing reported high levels of fortitude than participants with high levels of stress and low levels of fortitude.

Taken together, these findings suggest that fortitude is a protective factor. Positive appraisals of the self (e.g., as competent and capable), the family (e.g., as an accessible source of emotional support) and other supports within the environment (e.g., friends as a reliable source of support) facilitate adjustment in relation to potentially traumatic events and buffers against the negative effects of further exposure. Problematic appraisals in these three domains are associated with an increase in trauma-related symptoms. These findings also lend further support to studies emphasising the salience of cognitive appraisals in psychological outcome following trauma (Kleim et al., 2013; Park et al., 2012). Most 
research in this area has been on adults and, according to several theorists, (Bryant, Salmon, Sinclair, \& Davidson, 2007; Meiser-Stedman, Dalgleish, Glucksman, Yule, \& Smith, 2009), research concerning the role of these variables among youth has been limited. Our study therefore makes an important contribution to the adolescent literature on differential vulnerability in relation to traumatic events, specifically the role of appraisals related to fortitude.

The findings of this study also have implications for intervention. This study emphasises that psychological intervention efforts need to focus on adolescents' appraisal of the impact of the event and their ability to cope and their appraisals of the availability and utility of support resources within the family and larger environment. Cognitive-behavioural treatment (CBT) models for trauma and PTSD (Ford et al., 2015) have a strong focus on identifying and addressing problematic appraisals of the traumatic event and its sequelae (Kleim et al., 2013). However, these treatment approaches are under-utilised in local contexts (Edwards, 2010). This study offers support for the use of interventions that target appraisals associated with coping and advocates for the use of these interventions in local contexts.

\section{Conclusion}

For many adolescents in South Africa, exposure to violence is a frequent occurrence with significant psychological repercussions. It is thus essential that research efforts continue to identify the factors that contribute to differential vulnerability. This represents one of the few studies to examine fortitude among adolescents living in high risk communities. Our findings suggest that cognitive appraisals related to the self, family and broader supports have significant implications for coping with violence and that intervention efforts need to be tailored to focus on enhancing appraisals associated with coping. Currently, CBT treatment models have the strongest evidence base (Ford et al., 2015) and have a significant focus on addressing problematic appraisals so as to promote coping. 


\section{References}

Atwoli, L., Stein, D. J., Williams, D. R., Mclaughlin, K. A., Petukhova, M., Kessler, R. C., \& Koenen, K. C. (2013). Trauma and posttraumatic stress disorder in South Africa: Analysis from the South African Stress and Health Study. BMC Psychiatry, 13(1), 182. http://dx.doi.org/10.1186/1471-244X-13-182

Bonanno, G. A., \& Diminich, E. D. (2013). Annual Research Review: Positive adjustment to adversity- trajectories of minimal-impact resilience and emergent resilience. Journal of Child Psychology and Psychiatry, and Allied Disciplines, 54(4), 378-401. http://dx.doi.org/10.1111/jcpp.12021

Bovin, M. J., \& Marx, B. P. (2011). The importance of the peritraumatic experience in defining traumatic stress. Psychological Bulletin, 137(1), 47-67. http://dx.doi.org/10.1037/aoo21353

Bryant, R. A., Salmon, K., Sinclair, E., \& Davidson, P. (2007). A prospective study of appraisals in childhood posttraumatic stress disorder. Behaviour Research and Therapy, 45(10), 2502-2507. http://dx.doi. org/10.1016/j.brat.2007.04.009

Calhoun, L. G., \& Tedeschi, R. G. (2014). Handbook of posttraumatic growth: Research and practice. New York, NY: Psychology Press.

Cohen, J., \& Cohen, P. (1975). Applied multiple regression/correlation analysis for the behavioural sciences. Hillsdale, NJ: Erlbaum.

Copeland-Linder, N., Lambert, S. F., \& Ialongo, N. S. (2010). Community violence, protective factors, and adolescent mental health: A profile analysis. Journal of Clinical Child and Adolescent Psychology, 39(2), 176-186. http://dx.doi.org/10.1080/15374410903532601

DePrince, A. P., Chu, A. T., \& Pineda, A. S. (2011). Links between specific posttrauma appraisals and three forms of trauma-related distress. Psychological Trauma: Theory, Research, Practice, and Policy, 3(4), 430-441. http://dx.doi.org/10.1037/a0021576

De Villiers, M., \& Van den Berg, H. (2012). The implementation and evaluation of a resiliency programme for children. South African Journal of Psychology. SuidAfrikaanse Tydskrif vir Sielkunde, 42(1), 93-102. http:// dx.doi.org/10.1177/0o8124631204200110

Edwards, D. J. (2010). Using systematic case studies to investigate therapist responsiveness: Examples from a case series of PTSD treatments. Pragmatic Case Studies in Psychotherapy, 6(4). http://dx.doi.org/10.14713/ pcsp.v6i4.1047

Ford, J. D., Grasso, D. J., Elhai, J. D., \& Courtois, C. A. (2015). Posttraumatic stress disorder: Scientific and professional dimensions. Kidlington, Oxford: Academic press.

Gass, J. D., Stein, D. J., Williams, D. R., \& Seedat, S. (2011). Gender differences in risk for intimate partner violence among South African adults. Journal of Interpersonal Violence, 26(14), 2764-2789. http://dx.doi. org/10.1177/0886260510390960

Good, P. I., \& Hardin, J. W. (2012). Common errors in statistics (and how to avoid them) (4th ed.). Hoboken, New Jersey: John \& Wiley Publications. http://dx.doi.org/10.1002/9781118360125 
Hardaway, C. R., McLoyd, V. C., \& Wood, D. (2012). Exposure to violence and socioemotional adjustment in low-income youth: an examination of protective factors. American Journal of Community Psychology, 49(1-2), 112-126. http://dx.doi.org/10.1007/s10464-011-9440-3

Harris, G., \& Vermaak, C. (2015). Economic inequality as a source of interpersonal violence: Evidence from sub-Saharan Africa and South Africa. South African Journal of Economic and Management Sciences, 18(1), 45-57. http://dx.doi.org/10.17159/2222-3436/2015/v18n1a4

Heyns, P. M., Venter, J. H., Esterhuyse, K. G., Bam, R. H., \& Odendaal, D. C. (2003). Nurses caring for patients with Alzheimer's disease: Their strengths and risk of burnout. South African Journal of Psychology. Suid-Afrikaanse Tydskrif vir Sielkunde, 33(2), 80-85. http://dx.doi.org/10.1177/008124630303300202

Jain, S., Buka, S. L., Subramanian, S. V., \& Molnar, B. E. (2012). Protective factors for youth exposed to violence role of developmental assets in building emotional resilience. Youth Violence and Juvenile Justice, 1O(1), 107-129. http://dx.doi.org/10.1177/1541204011424735

Janoff-Bulman, R. (2010). Shattered assumptions. New York: The Free Press.

Jones, J. M. (2007). Exposure to chronic community violence resilience in African American children. The Journal of Black Psychology, 33(2), 125-149. http://dx.doi.org/10.1177/0095798407299511

Kleim, B., Grey, N., Wild, J., Nussbeck, F. W., Stott, R., Hackmann, A., ... Ehlers, A. (2013). Cognitive change predicts symptom reduction with cognitive therapy for posttraumatic stress disorder. Journal of Consulting and Clinical Psychology, 81(3), 383-393. http://dx.doi.org/10.1037/aoo31290

Meiser-Stedman, R., Dalgleish, T., Glucksman, E., Yule, W., \& Smith, P. (2009). Maladaptive cognitive appraisals mediate the evolution of posttraumatic stress reactions: A 6-month follow-up of child and adolescent assault and motor vehicle accident survivors. Journal of Abnormal Psychology, 118(4), 778-787. http://dx.doi.org/10.1037/aoo16945

Mollica, R. F., Capi-Yavin, Y., Bollini, P., Truong, T., Tor, S., \& Lavelle, J. (1992). Validating a cross-cultural instrument for measuring torture, trauma and posttraumatic stress disorder in Indochinese refugees. The Journal of Nervous and Mental Disease, 180, 111-116. Retrieved from http://dx.doi.org/1097/00005053199202000-00008 http://dx.doi.org/10.1097/00005053-199202000-00008

Noltemeyer, A. L., \& Bush, K. R. (2013). Adversity and resilience: A synthesis of international research. School Psychology International, 34(5), 474-487. http://dx.doi.org/10.1177/0143034312472758

O’Donnell, D. A., Roberts, W. C., \& Schwab-Stone, M. E. (2011). Community violence exposure and post-traumatic stress reactions among Gambian youth: The moderating role of positive school climate. Social Psychiatry and Psychiatric Epidemiology, 46(1), 59-67. http://dx.doi.org/10.1007/s00127-009-0162-x

Park, C. L., Mills, M. A., \& Edmondson, D. (2012). PTSD as meaning violation: Testing a cognitive worldview perspective. Psychological Trauma: Theory, Research, Practice, and Policy, 4(1), 66-73. http://dx.doi. org/10.1037/a0018792 
Potgieter, J. C., \& Heyns, P. M. (2006). Caring for a spouse with Alzheimer's disease: Stressors and strengths. South African Journal of Psychology. Suid-Afrikaanse Tydskrif vir Sielkunde, 36(3), 547-563. http://dx.doi. org/10.1177/008124630603600307

Pretorius, C., Walker, S., \& Heyns, P. M. (2009). Sense of coherence amongst male caregivers in dementia: A South African perspective. Dementia (London), 8(1), 79-94. http://dx.doi.org/10.1177/1471301208099046

Pretorius, T. (1998). Fortitude as stress resistance: Development and validation of the Fortitude Questionnaire (FORQ). http://dx.doi.org/10.1.1.464.1299

Pretorius, T. B. (1992). Problem-solving appraisal in the association of life stress and depression: A South African study. Psychological Reports, 71(7), 855-862. http://dx.doi.org/10.2466/PRo.71.7.855-862

Renner, W., Salem, I., \& Ottomeyer, K. (2006). Crosscultural validation of measures of traumatic symptoms in groups of asylum seekers from Chechnya, Afghanistan, West Africa. Social and Behavioural Sciences, 34(9), 1101-1114.

Seedat, M., van Niekerk, A., Jewkes, R., Suffla, S., \& Ratele, K. (2009). Violence and injuries in South Africa: Prioritising an agenda for prevention. Lancet, 374(9694), 1011-1022. http://dx.doi.org/10.1016/ So140-6736(09)60948-X

Shields, N., Nadasen, K., \& Pierce, L. (2008). The effects of community violence on children in Cape Town, South Africa. Child Abuse \& Neglect, 32(5), 589-601. http://dx.doi.org/10.1016/j.chiabu.2007.07.010

Shumaker, S. A., \& Brownell, A. (1984). Toward a theory of social support: Closing conceptual gaps. The Journal of Social Issues, 4O(4), 11-36. http://dx.doi.org/10.1111/j.1540-4560.1984.tbo1105.x

Suliman, S., Mkabile, S. G., Fincham, D. S., Ahmed, R., Stein, D. J., \& Seedat, S. (2009). Cumulative effect of multiple trauma on symptoms of posttraumatic stress disorder, anxiety, and depression in adolescents. Comprehensive Psychiatry, 5O(2), 121-127. http://dx.doi.org/10.1016/j.comppsych.2008.06.006

Swart, L. A., Seedat, M., \& Nel, J. (2015). The situational context of adolescent homicide victimization in Johannesburg, South Africa. Journal of Interpersonal Violence. PubMedID: 26545396.

Van Schalkwyk, I., \& Wissing, M. P. (2013). Evaluation of a programme to enhance flourishing in adolescents. In M. P. Wessing (Ed.), Well-Being Research in South Africa (pp. 581-605). New York, NY: Springer. http://dx.doi.org/10.1007/978-94007-6368-5_27

Ward, C. L., Artz, L., Berg, J., Boonzaier, F., Crawford-Browne, S., Dawes, A., ... van der Spuy, E. (2012).

Violence, violence prevention, and safety: A research agenda for South Africa. South African Medical Journal, 102(4), 215-218.

Ward, C. L., Flisher, A. J., Zissis, C., Muller, M., \& Lombard, C. (2001). Exposure to violence and its relationship to psychopathology in adolescents. Injury Prevention, 7(4), 297301. http://dx.doi.org/10.1136/ip.7.4.297

Wissing, M. P., \& Temane, Q. M. (2013). The prevalence of levels of well-being revisited in an African context. In M. P. Wessing (Ed.), Well-Being Research in South Africa 
(pp. 71-90). New York, NY: Springer. http:// dx.doi.org/10.1007/978-94-007-63685

Wissing, M. P., Wissing, J. A., du Toit, M. M., \& Temane, Q. M. (2006). Patterns of psychological well-being and satisfaction with life in cultural context. In A. Della Fave (Ed.), Dimensions of well-being: Research and intervention (pp. 14-33). Milano, Italy: FrancoAngeli.

Yeung, N. C., Lu, Q., Wong, C. C., \& Huynh, H. C. (2015). The roles of needs satisfaction, cognitive appraisals, and coping strategies in promoting posttraumatic growth: A stress and coping perspective. Psychological Trauma: Theory, Research, Practice, and Policy. http://dx.doi.org/10.1037/traooooo91

Zolkoski, S. M., \& Bullock, L. M. (2012). Resilience in children and youth: A review. Children and Youth Services Review, 34(12), 2295-2303. http://dx.doi.org/10.1016/j.childyouth.2012.08.009 